\title{
Serum Cystatin C, Kidney Injury Molecule-1, Neutrophil Gelatinase-Associated Lipocalin, Klotho and Fibroblast Growth Factor-23 in The Early Prediction of Acute Kidney Injury Associated With Sepsis in a Chinese Emergency Cohort Study
}

\section{Yuanyuan Pei}

Peking University Second School of Clinical Medicine: Peking University People's Hospital

\section{Guangping Zhou}

Peking University Second School of Clinical Medicine: Peking University People's Hospital

\section{Pengfei Wang}

Peking University Second School of Clinical Medicine: Peking University People's Hospital

\section{Fang'e Shi}

Beijing Medical University Second Hospital: Peking University People's Hospital

\section{Xiaolu Ma}

Peking University Second School of Clinical Medicine: Peking University People's Hospital Jihong Zhu ( $\nabla$ zhujihong64@sina.com )

Peking University Second School of Clinical Medicine: Peking University People's Hospital

\section{Research}

Keywords: sepsis, acute kidney injury, biomarkers, cystatin C, KIM-1

Posted Date: November 15th, 2021

DOI: https://doi.org/10.21203/rs.3.rs-1059386/v1

License: (c) (i) This work is licensed under a Creative Commons Attribution 4.0 International License. Read Full License

Version of Record: A version of this preprint was published at European Journal of Medical Research on March 11th, 2022. See the published version at https://doi.org/10.1186/s40001-022-00654-7. 


\section{Abstract}

Background: Acute kidney injury (AKI) was a common and critical complication of sepsis, and is associated with unacceptable morbidity and mortality. Current diagnostic criteria for AKI was insensitive for early detection. Novel biomarkers included cystatin C, KIM-1, NGAL, klotho and FGF-23 which can predict AKI earlier may allow immediate interventions. We aimed to determine the diagnostic performance of these biomarkers for detecting AKI in sepsis patients.

Methods: This prospective observational study was conducted from May 2018 and November 2020, enrolling sequential 162 sepsis patients. AKI's definition was according to 2012 KDIGO criteria and we divided patients into non-AKI $(n=102)$ and AKI $(n=60)$ groups. Serum levels of several AKI biomarkers were detected by ELISA. The relationship between biomarker levels on admission of AKI were analyzed and discrimination performances comparison were performed.

Results: AKI incidence was up to 37.0\% (60/162) during hospitalization. Compared with non-AKI group, both serum cystatin C, KIM-1, NGAL and FGF-23 were significantly elevated at admission in septic AKI patients. The areas under the receiver operating curves demonstrated that serum cystatin $\mathrm{C}$ had modest discriminative powers for predicting $\mathrm{AKI}$ after sepsis, and cystatin $\mathrm{C}$ combined with serum creatinine in the prediction of septic AKI increased the diagnostic sensitivity prominently.

Conclusion: Serum cystatin C, KIM-1, NGAL and FGF-23 levels are both increased in septic AKI patients. Our study provides reliable evidence that cystatin $C$ solely and combined with serum creatinine may accurately and sensitively predict septic AKI when patients on admission.

\section{Introduction}

Sepsis is a well-known life-threatening syndrome caused by a dysregulated host response to infection, which could lead to multiple organ dysfunction and high fatality ${ }^{[1-2]}$. Sepsis has become a global public health problem. There are approximately 30 million sepsis patients worldwide each year with numerous and heavy medical costs ${ }^{[1,3]}$. Acute kidney injury (AKI) is a common and critical complication of sepsis, with an incidence from $33-50 \%^{[2-3]}$. Both sepsis and AKI are independently associated with increased morbidity and mortality, length of stay, and cost of care, early detection is crucial to providing opportunities for successful intervention ${ }^{[1-4]}$.

The pathophysiological mechanisms of septic AKI is remain complicated and elusive. The diagnosis of AKI is presently based on an increase serum creatinine $(\mathrm{SCr})$ concentration or a decrease in urine output $^{[5]}$. The initial limitation of a definition that relies on dynamic change in $\mathrm{SCr}$ is establishing a baseline SCr. Meanwhile, SCr isn't an accurate indicator for the evaluation of renal function, which is a small molecular weight (113 Da) molecule freely filtered by the glomerulus and not reabsorbed by the renal tubules ${ }^{[6]}$. SCr increases proportionally to muscle mass, and hence varies with age, sex, ethnic group, and extreme diets ${ }^{[6]}$. Urine output is insensitive and is often measured accurately only in the 
intensive care unit (ICU). And in sepsis patients, oliguria appears to carry elevated significance, even by 3 to 5 hours, an association between oliguria and AKI may be detectable ${ }^{[7-8]}$. Therefore, it is an urgency for better biomarkers for AKI prediction in order to improve the prognosis of sepsis patients.

Recently, several biomarkers of early structural kidney injury such as cystatin C, kidney injury molecule1(KIM-1), neutrophil gelatinase-associated lipocalin (NGAL), klotho and fibroblast growth factor-23(FGF23) have been reported that may identify early AKI before a significant increase in SCr level, but are not widely used in septic $\mathrm{AKI}^{[2,9]}$.

Cystatin $C$ is a cysteine protease inhibitor which has a half-life of $1.5 \mathrm{~h}$ compared with SCr's $4 \mathrm{~h}$ half-life ${ }^{[6,}$ 10]. Therefore, after kidney injury, cystatin $C$ concentration could elevate earlier than $\mathrm{SCr}$, so that earlier diagnosis of $\mathrm{AKI}$ is detectable ${ }^{[6,10]}$. KIM-1 is a type 1 transmembrane glycoprotein expressed at high levels on the renal proximal tubules in the kidney ${ }^{[2,6]}$. NGAL is a $25-\mathrm{kD}$ a protein of the lipocalin superfamily, originally isolated from human neutrophils ${ }^{[2]}$, which increases in the plasma and urine 24 48 $\mathrm{h}$ before the elevation of $\mathrm{SCr}^{[11-12]}$.Klotho-FGF-23 axis is reported both as AKI's biomarkers and potential therapies lately ${ }^{[9,13]}$. Klotho is mainly expressed in the kidney distal tubule and FGF-23 is its upstream regulator ${ }^{[9,13]}$. However, it is not specific for the kidney and is also produced by other tissues.

The emergency department/room(ER) is the first consultation department for the vast majority of sepsis patients and many of them receive treatment in ER. Research in the United States show that more than 500,000 patients suspected of sepsis are treated in ER every year ${ }^{[14]}$. Nevertheless, current studies on sepsis are mainly conducted in the ICU, and data from ER are scarce. For ER as a window department, early diagnosis of septic AKI in it is more consequential and ponderable. Therefore, we performed a prospective study with sepsis patients in order to explore early biomarkers for AKI prediction at hospital admission and these biomarkers included measurements of glomerular function (cystatin C), proximal and distal tubule function (KIM-1 and klotho).

\section{Methods}

\section{Study Population}

The prospective observational study was conducted in the Peking University People's Hospital from China which included all 195 consecutive patients diagnosed with sepsis between May 2018 and November 2020 in emergency department, and enrolled 162 patients eventually. The following patients were excluded, (1) patients under the age of 18 years old(3 cases), (2) those with chronic kidney disease 3 to 5 stages (9 cases), defined according to the definition of the National Kidney Foundation as kidney damage or GFR of less than $60 \mathrm{ml} / \mathrm{min}$ per $1.73 \mathrm{~m}^{2}$ for at least 3 months, (3)patients' Child-Pugh classification of liver function was at B or C stage(4 cases), (4)with end-stage of malignant tumor(4 cases), (5) who died or were discharged within $48 \mathrm{~h}$ of admission (13 cases). Our study has been approved by the hospital ethics committee (No.2018PHB157-01). Patients or their family members were fully infor med of the study details and signed the informed consent forms of their own accord. 


\section{Definitions}

Sepsis and septic shock were defined according to the Third International Consensus Definitions for Sepsis and Septic Shock(Sepsis.3.0 ${ }^{[1]}$. The quick sequential organ failure assessment(qSOFA) was obtained when patients at admission, which used three criteria, assigning one point for low blood pressure (SBP $\leq 100 \mathrm{mmHg}$ ), high respiratory rate ( $\geq 22$ breaths per min), or altered mentation (Glasgow coma scale $<15)^{[1]}$. And according to the $2012 \mathrm{KDIGO}$ criteria, which was based on the RIFLE/AKIN definitions, we used the urine output and $\mathrm{SCr}$ components as indicates of $\mathrm{AKI}{ }^{[5]}$. The AKI is characterized by an increase in serum SCr of $0.3 \mathrm{mg} / \mathrm{dl}$ within $48 \mathrm{~h}$, an elevation on to $1.5 \mathrm{fold}$ the baseline level within the first 7 days, or a decline in urine output to not more than $0.5 \mathrm{~mL} / \mathrm{kg}$ per hour for at least 6 hours. The stage of AKI was in accordance with 2012 KDIGO criteria uniformly ${ }^{[5]}$.

\section{Collection of clinical data}

The patient records were reviewed to obtain comprehensive data on the baseline characteristics. Age, gender, co-morbidities, initial vital signs, the peak of lactate and Pa02/FiO2 were collected. To determine the severity of inflammation, the peak of white blood cell (WBC) count, neutrophils (NE), C-reactive protein (CRP) and procalcitonin (PCT) were recorded. In addition, we also recorded the patients' heart, liver and coagulation function and etiological examination laboratory indicators. Antibiotic and antiviral treatment, use of vasoactive drugs, use of glucocorticoid and use of non-steroidal anti-inflammatory drugs (NSAIDs) medication and diuretics were recorded. The maximum daily doses of intravenous loop diuretics were all converted to furosemide, expressed as $1 \mathrm{mg}$ bumetanide $\approx 20 \mathrm{mg}$ torsemide $\approx 40 \mathrm{mg}$ furosemide. Meanwhile, use of central vein catheterization (CVC), mechanical ventilation, renal replacement therapy, extracorporeal membrane oxygenation (ECMO) was also included.

Serum sampling and biomarker analyses

Serum sample for cystatin C, KIM-1, NGAL, klotho and FGF-23 were taken on the first time when patients diagnosed with sepsis at admission in emergency. SCr levels were detected on admission and every 24 hours in the first 7 days. All samples were centrifuged at $1500 \mathrm{rpm}$ for 10 minutes, and then stored at $-80^{\circ} \mathrm{C}$ until detection. All biomarkers were measured in duplicate by a single enzyme-linked immunosorbent assay(ELISA) according to the manufacturer's instructions. NGAL ELISA kits were from Abcam (ab113326), cystatin C ELISA Kits from Sigma(RAB0105),KIM-1 ELISA kits from R\&D Systems(DSKM100), Klotho ELISA kits from R\&D Systems,(DY5334-05) and FGF-23 ELISA kits from R\&D Systems(DY5334-05). The measured results were compared between patients with and without AKI. Laboratory investigators were all blinded to the clinical information throughout the study.

\section{Statistical analysis}

The primary analysis compared the AKI group with the non-AKI group. All variables were tested for a normal distribution through the Kolmogorov-Smirnov test. All descriptive statistics were summarized and displayed as the mean \pm standard deviation or the median (25 75\%). Continuous variables and normal 
distribution data were compared using independent sample $t$ tests. And continuous variables that not normally distributed were compared by using the Mann-Whitney $U$ test. Categorical data were tested by the Chi-square test or Fisher's exact test. $P<0.05$ was considered to be statistical significance.

Receiver operating characteristic (ROC) analysis was used to explore the ability of these biomarkers to predict AKI occurrence in patients with sepsis at admission. Discrimination was assessed based on the area under a receiver operating characteristic curve (AUROC). We described AUCs using the following values: $0.90 \sim 1.0$ excellent, $0.80 \sim 0.89$ good, $0.70 \sim 0.79$ fair, 0.60 0.69 poor and 0.50 0.59 no useful performance $\mathrm{e}^{[15]}$. The analysis of AUROC was also conducted to estimate the cut-off values, sensitivity and specificity, and cut-off points were calculated by determining the best Youden index. All analyses were performed with SPSS 25.0 software.

\section{Results}

Study population and incidence of AKI

Overall, 195 consecutive patients were screened. Of these, 33 patients were later excluded according to the exclusion and 162 patients enrolled in this study eventually. Among them, 37.0\% (60/162) patients developed AKI in the first 7days according to the 2012 KDIGO definition. Of the 60 AKI patients, 17 patients (28.3\%) developed stage1 AKI, 14 (23.3\%) developed stage 2 AKI, 29 (48.3\%) developed stage 3 $\mathrm{AKI}$ and 6 received renal replacement therapy. Compared to non-AKI group, the in-hospital mortality of the AKI group was obviously higher $(42.7 \%$ vs $11.8 \%, P<0.001)$.

Baseline characteristics

The demographic baseline clinical characteristics of the patients were listed in Table 1. Compared to the non-AKI group, the AKI group tend to have higher incidence of chronic heart disease (CHD) and chronic kidney disease (CKD). And patients with AKI had higher qSOFA score and Lac at admission. On auxiliary examinations, AKI group had more serious inflammation responses, worse cardiac and renal function, and severer coagulation system disorders, which manifested as significant increases in CRP, WBC, NE and PCT, higher levels of BNP, BUN and SCr and lower eGFR level, and the decrease of PTA and obvious elevation of d-dimer levels. However, it was worth pointing out that there is no statistical difference in patients' LVEF. CVC and mechanical ventilation and CRRT were apparently higher in AKI groups due to severer conditions. Meanwhile, more use of carbapenems and antifungal treatment, more use of vasoactive drugs included noradrenaline and metaraminol and larger doses of diuretics was observed in AKI group. 
Table 1

Baseline characteristics in sepsis patients

\begin{tabular}{|c|c|c|c|c|}
\hline Variables & $\begin{array}{l}\text { Total } \\
(n=162)\end{array}$ & $\begin{array}{l}\text { AKI group } \\
(n=60)\end{array}$ & $\begin{array}{l}\text { Non-AKI group } \\
(n=102)\end{array}$ & $\begin{array}{l}P \\
\text { value }\end{array}$ \\
\hline \multicolumn{5}{|l|}{ Demography } \\
\hline Age(years) & $72(58,83)$ & $75(59,84)$ & $70(58,83)$ & 0.324 \\
\hline Male(\%) & $97(59.9)$ & $39(65.0)$ & $58(56.9)$ & 0.325 \\
\hline Hypertention(\%) & $68(42.0)$ & $26(43.3)$ & $42(41.2)$ & 0.726 \\
\hline Diabetes mellitus(\%) & $49(30.2)$ & 19(31.7) & $30(29.4)$ & 0.448 \\
\hline $\begin{array}{l}\text { Chronic heart disease } \\
(\%)\end{array}$ & $43(26.5)$ & $22(36.7)$ & $21(20.6)$ & 0.029 \\
\hline $\begin{array}{l}\text { Chronic lung disease } \\
(\%)\end{array}$ & $25(15.4)$ & $6(10.0)$ & 19(18.6) & 0.175 \\
\hline Cerebral disease (\%) & $43(26.5)$ & 17(28.3) & $26(25.5)$ & 0.715 \\
\hline CKD $(\%)$ & $17(10.5)$ & $12(20.0)$ & $5(4.9)$ & 0.006 \\
\hline In-hospital motality & $37(22.8)$ & $25(42.7$ & 12(11.8) & 0.000 \\
\hline \multicolumn{5}{|l|}{ Clinical presentation } \\
\hline qSOFA score & $2(1,2)$ & $2(2,2)$ & $1(1,2)$ & 0.000 \\
\hline Heart rate(bpm) & $109 \pm 26$ & $114 \pm 30$ & $106 \pm 23$ & 0.061 \\
\hline $\begin{array}{l}\text { Systolic pressure } \\
(\mathrm{mmHg})\end{array}$ & $122 \pm 27$ & $117 \pm 28$ & $124 \pm 26$ & 0.112 \\
\hline $\begin{array}{l}\text { Diastolic pressure } \\
(\mathrm{mmHg})\end{array}$ & $67 \pm 16$ & $66 \pm 17$ & $68 \pm 16$ & 0.499 \\
\hline $\operatorname{Tmax}\left({ }^{\circ} \mathrm{C}\right)$ & $39.0 \pm 0.9$ & $39.0 \pm 1.1$ & $39.0 \pm 0.8$ & 0.690 \\
\hline $\mathrm{SpO}_{2}(\%)$ & $95(88,99)$ & $95(87,99)$ & $95(89,99)$ & 0.944 \\
\hline $\mathrm{Lac}(\mathrm{mmol} / \mathrm{L})$ & $1.9(1.1,3.8)$ & $2.8(1.5,6.0)$ & 1.6(1.1,2.7) & 0.000 \\
\hline $\mathrm{PaO}_{2} / \mathrm{FiO}_{2}(\mathrm{mmHg})$ & $230 \pm 94$ & $217 \pm 105$ & $238 \pm 86$ & 0.211 \\
\hline
\end{tabular}

Data expressed as mean \pm standard deviation, $n(\%)$, or median (interquartile range). CKD, chronic kidney disease. SCr, serum creatinine. eGFR, estimated glomerular filtration rate. FBG, fa sting blood glucose. CRE, Carbapenem-resistant enterobacteria. LVEF, left ventricular ejection fra ction. NSAIDs, Non-steroidal anti-inflammatory drugs. CVC, central vein catheterization. CRRT, continuous renal replacement therapy. ECMO, extracorporeal membrane oxygenation. Compared with non-AKI group, $P<0.05$ was considered significantly. 


\begin{tabular}{|c|c|c|c|c|}
\hline Variables & $\begin{array}{l}\text { Total } \\
(n=162)\end{array}$ & $\begin{array}{l}\text { AKI group } \\
(n=60)\end{array}$ & $\begin{array}{l}\text { Non-AKI group } \\
(n=102)\end{array}$ & $\begin{array}{l}P \\
\text { value }\end{array}$ \\
\hline CRP & $147.4(82.3,200)$ & $200(126.2,200)$ & $120(68.5,200)$ & 0.000 \\
\hline Hemoglobin (g/L) & $103 \pm 29$ & $96 \pm 32$ & $108 \pm 26$ & 0.016 \\
\hline WBC $\left(\times 10^{9} / \mathrm{L}\right)$ & $12.9(9.5,17.1)$ & $15.8(11.3,20.2)$ & $11.7(8.3,15.4)$ & 0.002 \\
\hline Neutrophils (\%) & $88.2(81.7,92.2)$ & $90.2(84.5,93.6)$ & $86.6(80.1,90.8)$ & 0.009 \\
\hline $\operatorname{PLT}\left(\times 10^{9} / \mathrm{L}\right)$ & $128(72,222)$ & $91(36,164)$ & $152(85,241)$ & 0.000 \\
\hline РСТ(ng/ml) & $2.635(0.422,8.338)$ & $6.960(1.870,25.600)$ & $1.220(0.204,4.350)$ & 0.000 \\
\hline $\begin{array}{l}\text { SCr at admission } \\
(\mu \mathrm{mol} / \mathrm{L})\end{array}$ & $73.0(58.5,120.0)$ & $144.0(78.5,231.0)$ & $68.0(52.5,91.0)$ & 0.000 \\
\hline $\mathrm{SCr} \operatorname{Max}(\mu \mathrm{mol} / \mathrm{L})$ & $90.0(64.5,191.1)$ & $221.0(149.5,316.3)$ & $72.0(56.5,91.5)$ & 0.000 \\
\hline $\begin{array}{l}\text { eGFR }(\mathrm{ml} / \mathrm{min} \\
\left.\star 1.73 \mathrm{~m}^{2}\right)\end{array}$ & $67.24(26.58,86.25)$ & $21.92(13.47,38.54)$ & $84.79(68.74,97.19)$ & 0.000 \\
\hline BUN (mmol/l) & $10.76(6.41,21.61)$ & $24.42(18.84,34.48)$ & 7.33(5.36,10.66) & 0.000 \\
\hline TNI(ng/ml) & $0.050(0.050,0.052)$ & $0.05(0.05,0.160)$ & $0.05(0.05,0.05)$ & 0.000 \\
\hline $\mathrm{BNP}(\mathrm{ng} / \mathrm{ml})$ & $196(65,521)$ & $419(100,1180)$ & $128(60,329)$ & 0.002 \\
\hline FBG (mmol/L) & $7.48(6.07,11.55)$ & $8.14(6.45,13.71)$ & 7.41(5.98,10.48) & 0.134 \\
\hline Albumin(g/L) & $29.9 \pm 5.9$ & $27.4 \pm 4.8$ & $31.5 \pm 6.0$ & 0.000 \\
\hline TBil $(\mu \mathrm{mol} / \mathrm{L})$ & $15.9(10.4,30.0)$ & $20.2(12.7,33.3)$ & $15.1(9.2,22.4)$ & 0.003 \\
\hline $\begin{array}{l}\text { Prothrombin activity } \\
(\%)\end{array}$ & $66 \pm 18$ & $61 \pm 20$ & $69 \pm 16$ & 0.008 \\
\hline Fibrinogen $(\mathrm{mg} / \mathrm{dl})$ & $458(374,569)$ & $479(328,601)$ & $452(396,550)$ & 0.721 \\
\hline D-dimer(ng/ml) & $1833(532,3394)$ & $3374(2174,7307)$ & $830(410,2035)$ & 0.000 \\
\hline $\begin{array}{l}\text { Hemoculture } \\
\text { positive(\%) }\end{array}$ & $27(16.7)$ & 11(18.3) & 16(15.7) & 0.668 \\
\hline $\begin{array}{l}\text { Other culture of } \\
\text { bacteria positive (\%) }\end{array}$ & $37(22.8)$ & $16(26.7)$ & $21(20.6)$ & 0.442 \\
\hline \multicolumn{5}{|c|}{$\begin{array}{l}\text { Data expressed as mean } \pm \text { standard deviation, } n(\%) \text {, or median (interquartile range). CKD, chronic } \\
\text { kidney disease. SCr, serum creatinine. eGFR, estimated glomerular filtration rate. FBG, fa sting blood } \\
\text { glucose. CRE, Carbapenem-resistant enterobacteria. LVEF, left ventricular ejection fra ction. NSAIDs, } \\
\text { Non-steroidal anti-inflammatory drugs. CVC, central vein catheterization. CRRT, continuous renal } \\
\text { replacement therapy. ECMO, extracorporeal membrane oxygenation. Compared with non-AKI group, } \\
P<0.05 \text { was considered significantly. }\end{array}$} \\
\hline
\end{tabular}




\begin{tabular}{|c|c|c|c|c|}
\hline Variables & $\begin{array}{l}\text { Total } \\
(n=162)\end{array}$ & $\begin{array}{l}\text { AKI group } \\
(n=60)\end{array}$ & $\begin{array}{l}\text { Non-AKI group } \\
(n=102)\end{array}$ & $\begin{array}{l}P \\
\text { value }\end{array}$ \\
\hline CRE positive (\%) & $8(4.9)$ & $4(6.7)$ & $4(3.9)$ & 0.474 \\
\hline Virus positive(\%) & $13(8.0)$ & $3(5.0)$ & $10(9.8)$ & 0.375 \\
\hline $\begin{array}{l}\text { Fungal culture positive } \\
(\%)\end{array}$ & $14(8.5)$ & $7(11.7)$ & $7(6.9)$ & 0.388 \\
\hline LVEF(\%) & $65 \pm 9$ & $63 \pm 12$ & $66 \pm 7$ & 0.174 \\
\hline \multicolumn{5}{|l|}{ Therapies } \\
\hline Carbapenems(\%) & $104(64.2)$ & $50(83.3)$ & $54(52.9)$ & 0.000 \\
\hline Penicillins(\%) & $76(46.9)$ & $24(40.0)$ & $52(51.0)$ & 0.195 \\
\hline Cephalosporin(\%) & $58(35.8)$ & 20(33.3) & 38(37.3) & 0.735 \\
\hline Quinolone(\%) & $111(68.5)$ & 43(71.7) & 68(66.7) & 0.600 \\
\hline Aminoglycosides(\%) & $32(19.8)$ & $15(25.0)$ & $17(16.7)$ & 0.223 \\
\hline Macrolide(\%) & $5(3.1)$ & $0(0)$ & $5(4.9)$ & 0.159 \\
\hline Sulfonamides(\%) & $5(3.1)$ & $2(3.3)$ & $3(2.9)$ & 0.613 \\
\hline Tetracycline(\%) & $4(2.5)$ & $3(5.0)$ & $1(1.0)$ & 0.144 \\
\hline $\begin{array}{l}\text { Gram-positive coccal } \\
\text { antibiotics }(\%)\end{array}$ & $36(22.2)$ & $15(25.0)$ & $21(20.6)$ & 0.560 \\
\hline Antiviral therapy(\%) & $26(16.1)$ & $10(16.7)$ & 16(15.7) & 0.518 \\
\hline Fungal antibiotics(\%) & $20(12.3)$ & 13(21.7) & $7(6.9)$ & 0.012 \\
\hline Dopamine(\%) & $8(4.9)$ & $6(10.0)$ & $2(2.0)$ & 0.053 \\
\hline Noradrenaline (\%) & $15(9.3)$ & 12(20.0) & $3(2.9)$ & 0.000 \\
\hline Metaraminol (\%) & 18(11.1) & 13(21.7) & $5(4.9)$ & 0.002 \\
\hline $\begin{array}{l}\text { Glucocorticoid therapy } \\
(\%)\end{array}$ & $38(23.5)$ & $14(23.3)$ & $24(23.5)$ & 0.568 \\
\hline NSAIDs (\%) & $8(4.9)$ & $1(1.7)$ & $7(6.9)$ & 0.260 \\
\hline $\begin{array}{l}\text { Use of furosemide } \\
\text { (mg/d) }\end{array}$ & $0(0,20)$ & $20(0,40)$ & $0(0,20)$ & 0.000 \\
\hline \multicolumn{5}{|c|}{$\begin{array}{l}\text { Data expressed as mean } \pm \text { standard deviation, } n(\%) \text {, or median (interquartile range). CKD, chronic } \\
\text { kidney disease. SCr, serum creatinine. eGFR, estimated glomerular filtration rate. FBG, fa sting blood } \\
\text { glucose. CRE, Carbapenem-resistant enterobacteria. LVEF, left ventricular ejection fra ction. NSAIDs, } \\
\text { Non-steroidal anti-inflammatory drugs. CVC, central vein catheterization. CRRT, continuous renal } \\
\text { replacement therapy. ECMO, extracorporeal membrane oxygenation. Compared with non-AKI group, } \\
P<0.05 \text { was considered significantly. }\end{array}$} \\
\hline
\end{tabular}




\begin{tabular}{|lllll|}
\hline Variables & $\begin{array}{l}\text { Total } \\
(\mathbf{n}=162)\end{array}$ & $\begin{array}{l}\text { AKI group } \\
(\mathbf{n}=60)\end{array}$ & $\begin{array}{l}\text { Non-AKI group } \\
(\mathbf{n = 1 0 2})\end{array}$ & $\begin{array}{c}\boldsymbol{P} \\
\text { value }\end{array}$ \\
\hline CVC $(\%)$ & $22(13.6)$ & $15(25.0)$ & $7(6.9)$ & 0.002 \\
\hline In-hospital surgery(\%) & $2(1.2)$ & $1(1.7)$ & $1(1.0)$ & 0.608 \\
\hline $\begin{array}{l}\text { Mechanical ventilation } \\
(\%)\end{array}$ & $15(9.3)$ & $10(16.7)$ & $5(4.9)$ & 0.022 \\
\hline CRRT(\%) & $6(3.7)$ & $6(10.0)$ & $0(0)$ & 0.000 \\
\hline ECMO(\%) & $2(1.2)$ & $2(3.3)$ & $0(0)$ & 0.136 \\
\hline $\begin{array}{l}\text { Data expressed as mean } \\
\text { kidney disease. SCr, serum creatinine. eGFR, estimated glomerular filtration rate. FBG, fa sting blood } \\
\text { glucose. CRE, Carbapenem-resistant enterobacteria. LVEF, left ventricular ejection fra ction. NSAIDs, }\end{array}$ \\
$\begin{array}{l}\text { Non-steroidal anti-inflammatory drugs. CVC, central vein catheterization. CRRT, continuous renal } \\
\text { replacement therapy. ECMO, extracorporeal membrane oxygenation. Compared with non-AKI group, } \\
P<0.05 \text { was considered significantly. }\end{array}$ \\
\hline
\end{tabular}

Discrimination performance and accuracy of biomarkers regarding septic AKI

As shown in Table 2, cystatin C, KIM-1, NGAL and FGF23 both increased significantly in AKI group. The ROC curves of biomarkers and $\mathrm{SCr}$ on admission were displayed in predicting development of AKI after sepsis in Table 3 and Figure 1. Areas showed that serum levels of cystatin $\mathrm{C}$ had a slightly better discriminative powers in prediction of AKI than SCr (AUROC $0.821,95 \%$ confidence interval, 0.752 to 0.891 and AUROC $0.813,95 \%$ confidence interval, 0.736 to $0.890, P<0.001$, respectively). In addition, cystatin C combined with SCr's AUROC was up to 0.847 (sensitivity 0.950 , specificity 0.700 ). The cut-off value for cystatin $C$ in predicting AKI was $10.4 \mu \mathrm{g} / \mathrm{ml}$, sensitivity and specificity values of cystatin $C$ in predicting AKI in sepsis patients was 0.767 and 0.802 . The cut-off value of $\mathrm{KIM}-1$ was $135.7 \mathrm{pg} / \mathrm{ml}$ and its sensitivity and specificity was 0.617 and 0.832 (AUROC 0.760 ). NGAL's cut-off value was $95.6 \mathrm{ng} / \mathrm{ml}$, which sensitivity and specificity was 0.300 and 0.931 respectively. The sensitivity and specificity was 0.583 and 0.594 for FGF-23, and its AUROC was 0.596 . Both NGAL, KIM-1 and FGF-23 didn't display preferable diagnostic values compared with $\mathrm{SCr}$. 
Table 2

Early biomarkers in sepsis patients

\begin{tabular}{|lllll|}
\hline & $\begin{array}{l}\text { Total } \\
(\mathbf{n = 1 6 2})\end{array}$ & $\begin{array}{l}\text { AKI group } \\
(\mathbf{n = 6 0})\end{array}$ & $\begin{array}{l}\text { Non-AKI } \\
\text { group(n=102) }\end{array}$ & Pvalue \\
\hline $\begin{array}{l}\text { Cystatin C } \\
(\mu \mathrm{g} / \mathrm{ml})\end{array}$ & $9.6(7.4,15.1)$ & $16.48(10.45,22.68)$ & $7.98(6.65,10.19)$ & 0.000 \\
\hline $\mathrm{NGAL}(\mathrm{ng} / \mathrm{ml})$ & $43.97(20.68,102.24)$ & $44.0(20.7,102.2)$ & $30.8(16.8,65.0)$ & 0.011 \\
\hline $\mathrm{KIM}-1(\mathrm{pg} / \mathrm{ml})$ & $87.2(46.8,172.7)$ & $173.7(69.9,363.5)$ & $58.2(32.6,119.3)$ & 0.000 \\
\hline klotho(pg/ml) & $92.2(45.4,130.7)$ & $96.1(47.2,147.1)$ & $89.1(42.9,123.2)$ & 0.363 \\
\hline FGF-23(pg/ml) & $300.0(101.0,934.4)$ & $380.0(145.7,1376.9)$ & $246.0(84.7,746.4)$ & 0.046 \\
\hline $\begin{array}{l}\text { Data expressed as mean } \pm \text { standard deviation. Compared with non-AKI group, } P<0.05 \text { was consi dered } \\
\text { significantly. }\end{array}$ & & & \\
\hline
\end{tabular}

Table 3

The areas under the receiver operating characteristic curves for serum levels of biomarkers and $\mathrm{SCr}$ in admission to predict AKI after sepsis

\begin{tabular}{|lcccccc|}
\hline & AUROC & $95 \% \mathrm{Cl}$ & P value & $\begin{array}{c}\text { Cut-off } \\
\text { value }\end{array}$ & Sensitivity & Specificity \\
\hline SCr $(\mu \mathrm{mol} / \mathrm{L})$ & 0.819 & $0.742-0.896$ & $<0.001$ & 100.0 & 0.601 & 0.901 \\
\hline Cystatin $\mathrm{C}(\mu \mathrm{g} / \mathrm{ml})$ & 0.830 & $0.760-0.897$ & $<0.001$ & 10.4 & 0.767 & 0.802 \\
\hline NGAL $(\mathrm{ng} / \mathrm{ml})$ & 0.620 & $0.529-0.711$ & 0.011 & 95.6 & 0.300 & 0.931 \\
\hline KIM-1 $(\mathrm{pg} / \mathrm{ml})$ & 0.765 & $0.683-0.838$ & $<0.001$ & 135.7 & 0.617 & 0.832 \\
\hline FGF-23 $(\mathrm{pg} / \mathrm{ml})$ & 0.596 & $0.506-0.686$ & 0.042 & 322.1 & 0.583 & 0.594 \\
\hline SCr+cystatin C & 0.847 & $0.777-0.917$ & $<0.001$ & & 0.950 & 0.700 \\
\hline AUROC, area under the receiver operating characteristic curves; Cl, confidence interval \\
\hline
\end{tabular}

\section{Discussion}

AKI is a common complication in sepsis patients, associated with a longer length of hospitalization and higher morbidity and mortality rate. In this investigation, the incidence of septic AKI is $37.0 \%$, nearly half of AKI patients (48.7\%) have displayed stage 3. Compared to previous studies, the proportion of stage AKI 3 patients in our cohort are relatively higher, which may be related to the population distribution of emergency patients ${ }^{[16]}$. Septic AKI group tends to more critical, accompanied with severer inflammation responses, worse cardiac function, and more coagulation dysfunction. Invasive procedures and treatments, use of vasoactive agents and higher grade antibiotic were also observed in the AKI group. On biomarkers associated with septic AKI, we found cystatin C, KIM-1, NGAL and FGF-23 were both elevated 
in AKI group. We analyzed the precision and discriminative ability of these biomarkers for prediction of septic AKI at admission. Compared with $\mathrm{SCr}$, cystatin $\mathrm{C}$ may be a more sensitive biomarker for septic AKI, while other biomarkers did not display diagnostic superiority. And cystatin C combined with $\mathrm{SCr}$ in the prediction of septic AKI increased the diagnostic sensitivity prominently.

Cystatin $C$ is a 13-kDa cysteine proteinase inhibitor produced by nucleated cells, and freely filtered by the glomerulus, reabsorbed but not secreted by the renal tubules ${ }^{[6]}$. Based on the above physiological characteristics, as a renal functional biomarker, cystatin $\mathrm{C}$ has been found to be superior to $\mathrm{SCr}$ in detecting minor reductions of GFR in a number of studies ${ }^{[17-19]}$. It was also confirmed in our study. However, some studies reported that severe systemic inflammation caused by sepsis could lead to the elevation of cystatin $C$, so the prediction of cystatin $C$ in septic AKI is negative, which needs further studies $^{[20]}$. We observed serum cystatin $C$ is significantly increased in the septic AKI group at admission. The cut-off value of cystatin $\mathrm{C}$ is $10.4 \mathrm{ng} / \mathrm{mL}$ (sensitivity, 0.767 ; specificity, 0.802 ; Youden index, 0.569 ) and AUROC of cystatin C is 0.830 . Meanwhile, the cut-off value of $\mathrm{SCr}$ is $100 \mu \mathrm{mol} / \mathrm{L}$ (sensitivity, 0.601 ; specificity, 0.901; Youden index, 0.502) and AUROC is 0.819 . And cystatin C combined with SCr's could improve AUROC to 0.847 and enhance its sensitivity to 0.950 with a slight decrease in specificity to 0.700 . Since one of the key points in the prevention and treatment of AKI is early detection, the improvement of diagnostic sensitivity is meritorious.

KIM-1 is a type 1 transmembrane glycoprotein contains extracellular mucin and immunoglobulin domains. It is observed that the expression of KIM-1 is mainly expressed in proximal tubule cells both in rodents and humans ${ }^{[21]}$. Basal expression of

KIM-1 is low in the normal kidney but could be dramatically upregulated after ischemia-reperfusion injury $\mathrm{AKI}$ and drug induced AKI models ${ }^{[21-22]}$. Moreover, KIM-1 has been reported which could play a role in renal recovery and tubular regeneration after $\mathrm{AKI}^{[23-24]}$. However, in clinical diagnostic studies, serum KIM-1 has found only modest results, which is the same as our study ${ }^{[25]}$. It is speculated that KIM-1 reflects the injury and repair function of kidney, concentration detection of KIM-1 may not be able to discriminate with high accuracy between AKI, which will injury or recover.

NGAL is a $25-k D a$ protein of the lipocalin superfamily that was originally isolated from human neutrophils, which has been extensively investigated in various AKI phenotypes ${ }^{[26-27]}$. Some studies also found that NGAL failed to discriminate patients with an AKI in the setting of sepsis ${ }^{[28]}$. Although NGAL has been considered as a biomarker of AKI, but it is not specific to the kidney and is also produced by other tissues such as neutrophils which synthesized NGAL's homodimer ${ }^{[26-27]}$. So NGAL may increase systemic infection and inflammation without evidence for AKI. Perhaps due to the physiological characteristics, the performance of NGAL was poor in our study.

Klotho-FGF23 signaling axis was found correlative with AKI ${ }^{[9]}$. Circulating FGF23 was reported increased and klotho was decreased in AKI rodent models, and treatment with klotho could improve kidney damage $[9,13,29]$. However, these two biomarkers were with poorly diagnostic value in septic AKI in our study. 
Our study had some limitations. Firstly, the sample size was relatively small, and all patients were from a single center. Secondly, biomarkers were only detected on admission, although it is more predictable for $\mathrm{AKI}$, but we did not monitor the $\mathrm{SCr}$ and biomarkers daily to show continuous changes. Thirdly, the biomarkers need to be proven in a general population without exclusion criteria, and especially in those who died in $48 \mathrm{~h}$ since it could not diagnose AKI according to current standard.

In summary, this study provides a perspective that cystatin C could be a more reliable and sensitive predictor for AKI as compared to SCr. And the combination with cystatin $\mathrm{C}$ and $\mathrm{SCr}$ has an outstanding diagnostic efficiency. Meanwhile, KIM-1, NGAL, klotho and FGF-3 did not display their superiority. Early detection of AKI may allow better therapy and potentially avoid its detrimental clinical outcome. Therefore, an improvement in sensitivity and decent specificity is estimable for emergency physicians in septic AKI's early diagnosis.

\section{Declarations}

Ethics approval and consent to participate

This study is approved by Peking University People's Hospital's ethics committee (No.2018PHB157-01). Patients or their family members were fully informed of the study details and signed the informed consent forms.

Consent for publication

Not applicable.

Availability of data and materials

The datasets used/analyzed about the study are available from the corresponding author on reasonable request.

Competing interests

The authors declare that they have no competing interests

Funding

The research and development fund of Peking University People's Hospital in 2018, Project No. RDY201815

Authors' contributions

Contribution to the concept or design of the work: Jihong Zhu. Access to informed consent and serum samples: Guangping Zhou, Pengfei Wang and Fang'e Shi. All authors read and approved the final manuscript 
Acknowledgements

Not applicable.

\section{References}

1. Singer M, Deutschman CS, Seymour CW, et al. The Third International Consensus Definitions for Sepsis and Septic Shock (Sepsis-3). JAMA 2016, 315: 801-810

2. Sadudee Peerapornratana, Carlos L Manrique-Caballero, Hernando Gómez, et al. Acute kidney injury from sepsis: current concepts, epidemiology, pathophysiology, prevention and treatment. Kidney Int, 2019, 96(5):1083-1099.

3. Armstrong BA, Betzold RD, May AK. Sepsis and septic shock strategies. Surg Clin North Am, 2017, 97(6):1339-1379.

4. Yang L, Xing G, Wang L,et al. Acute kidney injury in China:a cross-sectional survey. Lancet, 2015, 386(10002):1465-1471.

5. Kidney Disease: Improving Global Outcomes (KDIGO) Acute Kidney Injury Work Group. KDIGO clinical practice guideline for acute kidney injury. Kidney Int Suppl 2012, 2: 1-138.

6. Tan K, Sethi SK. Biomarkers in cardiorenal syndromes. Transl Res, 2014, 164 (2):122-134.

7. LeedahI DD, Frazee EN, Schramm GE, et al. Derivation of urine output thresholds that identify a very high risk of AKI in patients with septic shock. Clin J Am Soc Nephrol, 2014, 9:1168-1174.

8. Prowle JR, Liu YL, Licari E, et al. Oliguria as predictive biomarker of acute kidney injury in critically ill patients. Crit Care, 2011, 15: R172.

9. Christov M, Neyra JA, Gupta S, et al. Fibroblast Growth Factor 23 and Klotho in AKI. Semin Nephrol, 2019, 39(1):57-75.

10. Shlipak MG, Mattes MD, Peralta CA. Update on cystatin C: incorporation into clinical practice. Am J Kidney Dis, 2013, 62(3):595-603.

11. Supavekin S, Zhang W, Kucherlapati R,et al. Differential gene expression following early renal ischemia/reperfusion. Kidney Int 2003, 63:1714-1724.

12. Tecson KM, Erhardtsen E, Eriksen PM, et al. Optimal cut points of plasma and urine neutrophil gelatinase-associated lipocalin for the prediction of acute kidney injury among critically ill adults: retrospective determination and clinical validation of a prospective multicentre study. BMJ Open. 2017, 7(7):e016028.

13. Javier A. Neyra, Ming Chang Hu and Orson W. Moe. Klotho in Clinical Nephrology: Diagnostic and Therapeutic Implications. Clin J Am Soc Nephrol, 2020, 16 (1):162-176.

14. Armstrong BA, Betzold RD, May AK. Sepsis and septic shock strategies. Surg Clin North Am, 2017, 97(6):1339-1379.

15. Glassford NJ, Schneider AG, Xu S, Eastwood GM, Young H, Peck L, et al. The nature and discriminatory value of urinary neutrophil gelatinase associated lipocalin in critically ill patients at 
risk of acute kidney injury. Intensive Care Med, 2013, 39 (10):1714-1724

16. Mårtensson J, Jonsson N, Glassford NJ, et al. Plasma endostatin may improve acute kidney injury risk prediction in critically ill patients. Ann Intensive Care, 2016, 6(1):6.

17. Dharnidharka VR, Kwon C, Stevens G. Serum cystatin $C$ is superior to serum creatinine as a marker of kidney function: a meta-analysis. Am J Kidney Dis 2002; 40: 221-226.

18. Mussap M, Dalla Vestra M, Fioretto $P$ et al. Cystatin $C$ is a more sensitive marker than creatinine for the estimation of GFR in type 2 diabetic patients. Kidney Int 2002; 61: 1453-1461.

19. Ah Young Leem1, Moo Suk Park, Byung Hoon Park, et al. Value of serum cystatin C measurement in the diagnosis of sepsis-induced kidney injury and prediction of renal function recovery. Yonsei Med $\mathrm{J}$, 2017, 58(3):604-612.

20. Johan Mårtensson, Claes-Roland Martling, Anders Oldner, et al. Impact of sepsis on levels of plasma cystatin C in AKI and non-AKI patients. Nephrol Dial Transplant, 2012, 27: 576-581.

21. Ichimura T, Bonventre JV, Bailly V, et al. Kidney injury molecule-1 (KIM-1), a putative epithelial cell adhesion molecule containing a novel immunoglobulin domain, is up-regulated in renal cells after injury. J Biol Chem,1998, 273: 4135-4142.

22. Joseph L Alge, John M Arthur. Biomarkers of AKI: a review of mechanistic relevance and potential therapeutic implications. Clin J Am Soc Nephrol, 2015, 10(1):147-155.

23. Ichimura T, Asseldonk EJ, Humphreys BD, et al. Kidney injury molecule-1 is a phosphatidylserine receptor that confers a phagocytic phenotype on epithelial cells. J Clin Invest 2008,118: 1657-1668.

24. Parikh CR, Thiessen-Philbrook H, Garg AX, et al. TRIBE-AKI Consortium: Performance of kidney injury molecule-1 and liver fatty acid binding protein and combined biomarkers of AKI after cardiac surgery. Clin J Am Soc Nephrol, 2013, 8: 1079-1088.

25. C-F Zhang 1, H-J Wang, Z-H Tong, et al. The diagnostic and prognostic values of serum and urinary kidney injury molecule-1 and neutrophil gelatinase-associated lipocalin in sepsis induced acute renal injury patients. Eur Rev Med Pharmacol Sci, 2020, 24(10):5604-5617.

26. Cai L, Rubin J, Han W, et al. The origin of multiple molecular forms in urine of HNL/NGAL. Clin J Am Soc Nephrol, 2010, 5(12):2229-2235.

27. Devarajan P. Review: neutrophil gelatinase-associated lipocalin: a troponin-like biomarker for human acute kidney injury. Nephrology (Carlton), 2010, 15(4):419-428.

28. Di Nardo M, Ficarella A, Ricci Z, et al. Impact of severe sepsis on serum and urinary biomarkers of acute kidney injury in critically ill children: an observational study. Blood Purif, 2013, 35:172-176.

29. Aiello S, Noris M. Klotho in acute kidney injury: biomarker, therapy, or a bit of both? Kidney Int, 2010, 78(12):1208-1210.

\section{Figures}



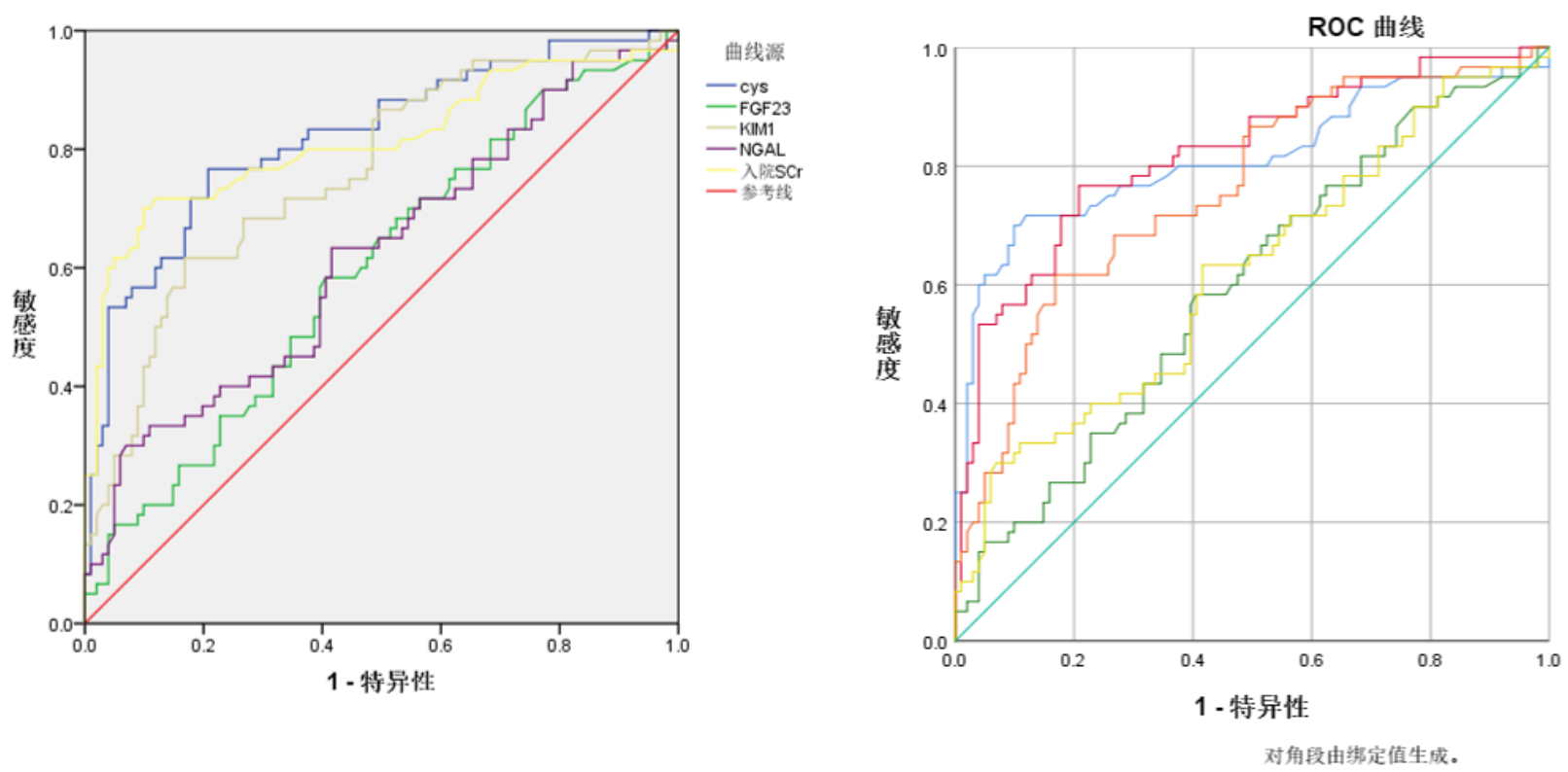

曲线来源

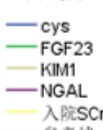

一考考战

\section{Figure 1}

The ROC curves of biomarkers and SCr on admission were displayed in predicting development of AKI after sepsis in Table 3 and Figure. 